\title{
COGNITIVE-BEHAVIORAL INTERVENTIONS IN THE PSYCHOANALYTIC PSYCHOTHERAPY OF BORDERLINE PERSONALITY DISORDERS ${ }^{1}$
}

\author{
Drew Westen \\ University of Michigan
}

\begin{abstract}
A pathology of affect regulation and of object relations (the cognitive and affective processes that mediate interpersonal functioning in close relationships) are two features that define much of borderline pathology. Cognitive-behavioral interventions that target self-regulation and social-cognitive processes (such as perspective-taking and attribution) can be usefully integrated into psychodynamically oriented treatment of borderline patients. Strictly psychodynamic approaches tend to be limited by factors such as a lack of attention to processes by which conscious insight and coping strategies can be transformed into automatic or adaptive unconscious procedures in these patients. Cognitive approaches tend to be limited by rationalistic assumptions about motivation and an underestimation of the complexities of cognitive-affective interactions and unconscious processes.
\end{abstract}

If researchers and clinicians who study borderline personality disorders (BPD) agree on one thing, it is that treatment of these patients is extremely difficult and frequently unsuccessful (see Waldinger, 1987). Waldinger and Gunderson (1984) found that, for borderline patients of experienced clinicians, only half continued in treatment beyond six months, only one-third completed treatment, and the majority terminated against their therapist's advice. ${ }^{2}$ Pharmacotherapy for borderline patients can sometimes be helpful, especially when used adjunctively with psychotherapy. However, medication typically produces modest results, sometimes generates unwanted effects [such as behavioral dyscontrol or impulsivity

\footnotetext{
${ }^{1}$ A version of this article was presented at the Third Annual Convention of the Society for the Exploration of Psychotherapy Integration, Chicago, IL, May, 1987.

${ }^{2}$ What is particularly sobering about these findings is that these patients were apparently relatively high-functioning borderlines, treated in private practice as outpatients, and that their therapists were largly clinicians who have made important contributions to the borderline literature.

Correspondence should be addressed to Drew Westen, Department of Psychology, University of Michigan, Ann Arbor, MI 48109-1346.
} 
when benzodiazepines are used to treat anxiety symptoms (Gardner \& Cowdry, 1985)], and is often not as efficacious with these patients as in nonborderline patients with similar Axis I pathology (Cowdry \& Gardner, 1988; Goldberg, Schultz, Resnick, Hamer, \& Friedel, 1986; Gunderson, 1986; Liebowitz, Stone, \& Turkat, 1986; Pilkonis \& Frank, 1988; Soloff et al., 1986).

The tendency of borderline patients to draw particular countertransference constellations should lead to special circumspection in altering therapeutic technique or adopting new treatment strategies. For example, BPDs tend to elicit wishes to save and wishes to kill, complementary to their wishes to be magically protected and to destroy. These may evoke therapist responses such as suffocating pseudo-nurturance that denies the patient's aggression and sense of entitlement; hostile interpretations or "showdowns," disguised as necessary confrontations; or aggressive use of multiple medications with limited efficacy, used to quell the therapist's anxiety or feelings of helplessness or to punish or subdue the patient. Limitations of current approaches to the treatment of borderline disorders, however, clearly suggest the need for continued consideration of other therapeutic interventions that may prove beneficial, particularly in light of the dearth of empirical evidence supporting the efficacy of traditional treatments.

Behavioral and cognitive-behavioral paradigms have historically lacked the theoretical tools to grapple with the complexities of personality disorders. Hunt's (1977) work on behavioral perspectives in the treatment of borderline patients is a highly perspicacious exception, although Hunt, like others (Lehrer, Schiff, \& Kris, 1971), focuses on the integration of operant conditioning principles into psychodynamically oriented inpatient programs. The high rate of comorbidity of BPD and mood disorders (Gunderson \& Elliot, 1985; Kroll \& Ogata, 1987) suggests that many patients treated by cognitive therapists for depression may have concurrent borderline pathology, although this is seldom discussed in the cognitive-behavioral literature (see Freeman \& Leaf, 1989). Cognitive-behavioral theories lack the conceptual scaffolding to distinguish depression as found in borderlines from nonborderline depression, which may have very significant implications for treatment. ${ }^{3}$ Recent research comparing borderline with depressed subjects using the Blatt et al. (1982) Depressive Experiences Questionnaire with both adolescent and adult samples has documented the psychoanalytic view (see Gunderson, 1984; Kernberg, 1975; Masterson, 1976) that BPDs suffer from a qualitatively distinct kind of depression, characterized by emptiness, loneliness, desperation in relation to attachment figures, and labile, diffuse negative affectivity (Wixom, 1988; Westen, Moses, Silk, et al., 1989).

Recently, borderline pathology has begun receiving more attention from cognitive-behavioral clinicians. Linehan $(1987 \mathrm{a}, 1987 \mathrm{~b}, 1987 \mathrm{c})$ has been developing a cognitive-behavioral model for understanding and treating borderline patients,

\footnotetext{
${ }^{3}$ Astute cognitive-behavioral clinicians are well aware of the diagnostic and prognostic importance of the distinction. In speaking with several cognitive-behavioral colleagues nationally, it appears that they typically do not trcat borderline patients, do not expect much therapeutic success with borderline patients who are depressed, or adjust their treatments to include a substantial focus on patient-therapist interactions and expect the treatment to last a period of years rather than months. Recent efforts to address personality disorders from a cognitive perspective (Beck, Freeman et al., 1990; Freeman \& Leaf, 1989) are very preliminary, largely translating DSM III-R criteria into schema language.
} 
which focuses particularly on dysfunctional mechanisms for regulating aversive affect states and on self-damaging acts such as suicidal gestures. Linehan's treatment program, which includes a mixture of group therapy, individual treatment, and psychoeducational training, tries to help borderline patients develop more adequate responses for coping with affect and for solving interpersonal problems. In contrast to more standard cognitive therapies, Linehan (1987b) emphasizes that "the emotional system is often the primary system and cannot always be readily accessed or changed by modifications in the cognitive system" (p. 152). Swenson (1989) has addressed ways Linehan's approach may be compatible and incompatible with Kernberg's psychodynamic psychotherapy for borderline patients. In addition to Linehan's system, Glat (1988) has suggested that Lazarus' (1981) multimodal therapy may offer a more sophisticated way of conceptualizing and treating the complexities of the borderline patient from a cognitive-behavioral point of view.

The aim of this article is to describe integrations of cognitive-behavioral interventions into the psychoanalytic psychotherapy of borderline patients. Although the focus will be primarily on patients who meet DSM-III-R criteria for $B P D$, many of the issues will be applicable to a broader spectrum of patients with severe personality disorders who meet Kernberg's $(1975$, 1984) criteria for borderline personality organization. While psychotherapy integrations have been occurring with increasing frequency in the past decade with other patient populations (Goldfried et al., 1989), it is crucial that such integrations occur in the context of integrated theories of personality, psychopathology, and technique, lest clinicians practice a "willy-nilly" eclecticism that leads only to incoherent treatments. The article will thus first suggest a framework for conceptualizing borderline pathology which points to specific avenues for integration of cognitive-behavioral techniques.

\section{AFFECTIVE DYSREGULATION AND PATHOLOGY OF OBJECT RELATIONS IN BORDERLINE PERSONALITY DISORDER}

Two features define much of the pathology of the borderline syndrome ${ }^{4}$ : affective dysregulation and pathological object relations. Identification of these two aspects of borderline pathology, which are typically intertwined, as pathognomonic or as generative of much of the diverse symptomatology of borderline disorders is not new. Millon (1981), Linehan (1987a), and Klein (1977) have focused on affective dysregulation from social learning and biological perspectives, whereas psychoanalytic theories (e.g., Buie \& Adler, 1982; Kernberg, 1975; Masterson, 1976) tend to focus more on the object-relational pathology of these patients. Sheehy, Goldsmith, \& Charles (1980) found, using a symptom checklist, that pathology of interpersonal functioning, affect modulation, and impulsivity most clearly identify borderline patients, and Clarkin (1983) identified the same three symptoms as the

\footnotetext{
${ }^{4}$ These features best define the core of "pure" borderline pathology, but they explain less of the pathology of nixed personality disorders. Borderline-schizoid or borderline-schizotypal patients, for example, have more prominent cognitive disturbance and less prominent affective dysregulation. Whether peculiarities in borderline cognition (see Gartner, Hurt, \& Gartner, 1989; Silk, Lohr, Westen, \& Goodrich, 1989; Zanarini, Gunderson \& Frankenberg, 1990) will constitute a third defining feature of BPD independent of the first two remains an open question.
} 
most frequent symptoms in borderlines. (As will be argued below, impulsivity can be understood using a model of affect regulation and motivation.)

\section{Affective Dysregulation in Borderlines}

Borderline patients manifest an extreme difficulty in regulating their emotions. When they are upset, the world is blark; when they are finding a relationship gratifying or are craving dependence, they see the person as a savior or magical "protector." Perry and Klerman (1980) found affective instability to be the clearest of several features in discriminating borderline from other psychiatric disorders. As Masterson (1976) aptly describes the affective life of the person with BPD, "we might say that the excursions of the pendulum in the psychological world of the borderline patient cover an infinitely wider amplitude than in the world of the neurotic" (p. 17). Ekstein and Wallerstein (1954), in describing borderline children, proposed that a normal aspect of ego structure operates much like a thermostat in maintaining "ego states" within a relatively consistent range. Borderline patients, in contrast, appear to have a "broken thermostat," leading to affect states, defenses, and impulsive behaviors which spiral out of control. Anxiety, rage, and depression centering on abandonment figure prominently in psychoanalytic accounts of BPD (Kernberg, 1975; Masterson, 1976). As one borderline research subject described it, "Feelings sometimes feel like they're a person and invade me. They push the real me off into the corner." In recent research interviews with patients previously reliably diagnosed as borderline and no longer diagnosed as such years later, colleagues and I repeatedly heard patients" explanations of their personality change such as, "I just realized I was overreacting to everything, and 1 had to stop it" (see Silk, Lohr, Ogata, \& Westen, 1990).

Drawing upon a number of sources (particularly Bowlby, 1969), Westen (1985) has developed a model of affect and affect-regulation that integrates aspects of psychoanalytic and cognitive-behavioral theories of motivation and self-regulation. In broadest outline, affect is seen as a mechanism for the selection of behavioral, defensive, and coping responses. A mental or behavioral process that is cognitively associated with minimization of negative or maximization of positive affect will be reinforced (made likely to be retained or used again) by its affective consequences. Affect may arise in a number of ways, including, as in control theory (and Freud's theory of signal anxiety; see Menninger, Mayman, \& Pruyser, 1963) as a feedback signal to alert the person of discrepancies between emotionally invested goals and cognized reality. This may occur consciously or unconsciously, as may selection of responses to alter or maintain the signal (for experimental and clinical evidence, see Westen, 1985, Chapter 2). For examplc, a borderline patient may fcel intensely ashamed, guilty, and afraid after verbally attacking a significant other because this action violates a number of emotionally invested goals, including ideal-self standards and wishes to maintain the relationship. This emotional state could motivate any number of responses previously associated with regulation of negative affect, such as wrist-slashing (a behavior that can be used for numbing or penance), splitting and projection (seeing the person as evil, worthless, and provocative of the abuse-an unconscious defense), or problem-solving ways to resolve the situation (a coping strategy). Obviously one aim of treatment with borderline (and other) patients is to alter dysfunctional hierarchies of response activation. 
If one examines DSM-III and DSM-III-R criteria for BPD, one finds that many of the criteria can be explained in whole or in part in terms of affective dysregulation. Impulsivity or unpredictability in self-damaging ways, in large measure, reflects a deficit in affect regulation, which leads the patient to act behaviorally instead of mentally, to fail to delay an impulse long enough for reflection, and to respond with behaviors as extreme as the affects motivating them. While, as will be argued below, the pattern of unstable and intense interpersonal relationships characteristic of borderlines is best conceived as a second core aspect of borderline pathology, it is nonetheless intertwined with problems of affect regulation. One of the major ways borderline patients regulate their dysphoria is by latching onto an attachment figure for the purpose of self-soothing; they also have difficulty staying in relationships when they get upset or do not feel gratified. Inappropriate, intense anger or lack of control of anger is a direct example of affective dysregulation, as is affective instability. While identity disturbance cannot be understood primarily with reference to pathological affect regulation, it is related in a number of ways. For instance, borderline patients often seem to jump from one intense affective experience to another, precluding any subjective experience of continuity of their own thoughts and feelings over time; indeed, because of their impulsivity and often contradictory behavior, any observer of their behavior, borderline or otherwise, may have difficulty piecing together a cohesive image of them. Intolerance of being alone, while best conceptualized as an aspect of borderline objectrelational pathology, also reflects the borderline patient's deficiency in the ability to self-soothe. Research on attachment in developmental psychology is coming increasingly to stress the relation between affect regulation, self-soothing, and patterns of interpersonal functioning (Kobak \& Sceery, 1988). The physically self-damaging acts and suicidal gestures characteristic of borderline patients in part reflect their impulsivity, their experience of overwhelming depression, and their inability to find more appropriate, tempered ways of regulating aversive affective states. Such patients frequently explain that they cut themselves as a way of numbing, relieving anxiety, or discharging anger. Linehan (1987a) emphasizes such an affect-regulatory aspect of borderline cutting and "parasuicides." The borderline patient's chronic feelings of emptiness and boredom may largely reflect a failure to internalize self-soothing functions and to invest emotionally over time in relationships, goals, and ideals. The chronic boredom of a subset of BPDs may also reflect a residual neurologically based deficit in attention regulation (see Andronulis et al., 1980), although this is speculative given the paucity of clear and consistent findings on neurological dysfunction in BPD (see Cornelius et al., 1989). Finally, DSM-III-R adds interpersonal exploitativeness to the borderline criteria. While, again, this is an aspect of borderline object-relational pathology, it also reflects an inability to invest emotionally in others in mature ways and to weigh the needs of others when one's own needs or affects are pressing. ${ }^{5}$

\footnotetext{
${ }^{5}$ In examining the contributions of affect-regulatory deficits in DSM-III and DSM-III-R borderline criteria, I do not mean to suggest that all borderline symptomatology can be reduced to this function. An affect-dysregulation hypothesis has recently been offered for mood disorders (Siever \& Davis, 1985), and both object-relational pathology and a more general pathology of the regulation and experience of affective states (beyond depression or even anxiety; see Benjamin et al., 1989) distinguish BPDs from patients with major depressive disorders who are not comorbid for BPD or related personality disorders (such as narcissistic and histrionic).
} 


\section{Object-Relational Pathology in Borderlines}

Pathology of object relations is a second core feature of borderline psychopathology which has been described by Kernberg, Masterson, and others. The concept of "object relations," however, is actually a shorthand for a constellation of cognitive and affective processes mediating interpersonal functioning that have interdependent but distinct developmental trajectories (Westen, 1989, in press). Delineation of specific cognitive and affective processes underlying pathological interpersonal functioning in borderlines suggests avenues for integration of more cognitively oriented interventions. (For empirical evidence of these processes in borderline patients, see Westen, 1991; Westen, Lohr, Silk, Gold, \& Kerber, 1990; Westen, Ludolph, Lerner, Ruffins, \& Wiss, 1990.)

\section{Affective-Motivational Aspects of Borderline Object Relations}

Four affective-motivational factors characterize borderline object relations. The first is a pathology of emotional investment in relationships. Borderline patients have unstable attachments. While at times they overinvest in someone who has quickly become assimilated to an unrealistic schema (such as a "good mother" or "benevolent other" of some sort), at other times they cannot maintain a consistent attitude toward someone whom they love who is currently not being gratifying. Second, borderline patients are aggressive (Kernberg, 1975). Whether this stems from a history of neglect, symbiotic parental overinvolvement (see Soloff \& Millward, 1983), physical or sexual abuse (Herman, Perry, \& van der Kolk, 1989; Ogata et al., 1990; Westen, Ludolph, Misle, Ruffins, \& Block, 1990), constitutional hyperactivity or dyscontrol (Andronulis et al. 1980), or some interaction of these, such patients' interpersonal relations are plagued by aggressive outbursts and sadism. Third, and related, is a characterologic masochism that typically alternates with sadism. In many cases, this may reflect a compulsion to repeat earlier abuse, while in other cases, the wish to be hurt reflects a developmentally primitive mechanism to allay poorly modulated guilt. Finally, borderline patients have a particular sensitivity to loss, rejection, and abandonment (Masterson, 1976). Research by Perry and Cooper (1986) has begun to document interpersonal concerns that distinguish borderlines from other patient groups.

\section{Lack of Integration of Representations of People}

Borderline self- and object-representations (or, from a cognitive-behavioral perspective, self-schemas and person-schemas) tend to be poorly integrated (Kernberg, 1984; Kernberg, Selzer, Koenigsberg, Carr, \& Appelbaum, 1989) and highly variable in their complexity and differentiation. These patients have tremendous difficulty bringing to mind representations of self and others that do not fit with their current affect state or motivation. At times this is done defensively, as when an adolescent patient would "forget" about positive aspects of his mother when he would want to steal things from her. The same patient, while in the midst of a powerful negative transference following my setting boundaries on his "emergency" calls, felt so angry and rejected that he could not tolerate looking me in the face. Instead of leaving the session, which he knew he needcd, he simply turned his chair around and began working with me as if I were the "old" Dr. Westen who had not so badly hurt him. He seems in this case to have been able to segregate his 
representations of me so thoroughly by affect-tone that by turning his chair around he could activate the more benign representation in the service of getting help and ultimately healing the split. As will be elaborated, at other times these patients appear to lack the capacity to maintain differentiated, integrated, and multifaceted representations of self and others when their emotions are aroused.

\section{Borderline Attributional Style}

A third aspect of borderline object relations is what one might call a "borderline attributional style." In everyday life, people attribute causes to their own and others' behaviors, thoughts, and emotions. Research with depressed subjects has documented the tendency of such people to have a depressive attributional or explanatory style, in which negative events are construed as one's own fault (an "internal" attribution), are expected to recur (for a review, see Peterson and Seligman, 1984). Borderline attributions tend to have the following four qualities:

1. Egocentric. Egocentrism in Piagetian theory refers to a relative lack of differentiation of the perspectives of self and other (Piaget, 1926), or an "embeddedness in one's own point of view" (Looft, 1972). Borderline attributions tend to be profoundly egocentric (for empirical evidence, see Exner, 1986; Westen, Lohr, Silk, et al., 1990). This egocentrism is manifest in three ways: (a) Borderline attributions tend to be intensely personal. The self is viewed as the causal center of the social universe. Whereas depressives tend to make internal attributions (self as cause) of bad events and external attributions (situation as cause) of good ones, borderline attributions are less stable but can often be characterized as "internal-external": "she did that because of the way she feels about me." (b) Because of their tendency to use defenses such as projection and to fail to differentiate their own and others' points of view, borderlines often attribute their own motives to others and vice versa. (c) Borderline patients sometimes suspend attributional processes entirely, concerned only with their own situation and feelings. For example, one patient told his therapist, after the patient forgot about the therapist's vacation and appeared for his session, that if he ever came again for a session and the therapist was not there, he would be so devastated that he would never return. The causes of the therapist's absence, he added, were immaterial because he would simply be so hurt.

2. Malevolent. Borderline patients have a tendency to attribute malevolence in explaining events. Knight (1953) pointed to this tendency to place blame for misfortune on external, malevolent forces. Kernberg (1975) views interpretation of negative transference as critical in psychotherapy with borderlines, in part because of their pervasive expectation that the therapist will be malevolent.

3. Inaccurate. Borderline patients' attributions are frequently inaccurate. Whereas, at times, their attributions are distorted by motivational factors, at other times this inaccuracy reflects peculiarities of borderline thinking (see Silk, Lohr, Westen, \& Goodrich, 1989; Zanarini, Gunderson, \& Frankenberg, 1990) or a social learning history in which parental actions were erratic and difficult to explain (see Westen, Ludolph, Block, et al., 1990).

4. Affect-centered. Finally, borderline attributions tend to be affect-centered. 
Borderlines' attributional processes tend to become polarized by affect, with attribution of "good" motives to "good" people and "bad" motives to "bad" people. Borderline attributions also become global when affect is aroused. Relatively minor events may become catastrophic because, for example, a univalent representation is activated (e.g., "she left me because I'm worthless," or "you refuse to treat me if I don't pay for sessions because you're a greedy person who just likes to hurt people"). With borderline patients, as opposed to nonborderline depressives, such globality of attribution probably applies equally to positive affective arousal ("she's doing that because she's just a wonderful person") and to others as well as the self. Borderline attributions are also highly susceptible to affective and motivational biases. While this is true of normal attributional processes, the greater intensity and peremptory quality of borderlines' affects leads to a heightened need to distort cognitions as well as simply a greater tendency for affective processes to infiltrate and bias cognition. Borderline attributional style is unstable (and difficult to measure) because it is so affect-centered and variable.

\section{COGNITIVE-BEHAVIORAL TECHNIQUES TARGETING PATHOLOGICAL AFFECT REGULATION AND OBJECT RELATIONS}

Most of what are called "supportive," "ego-supportive," or "ego-building" interventions in psychodynamic psychotherapy are aimed at helping patients regulate their affects and impulses. Defense analysis with borderlines has this as one of its major functions. Interpreting splitting and working with the patient to help her see that she felt otherwise three days earlier, or that she saw the therapist or someone else quite differently before a current idealization or devaluation, is a technique aimed at altering a pathological affect-regulatory process (see Kernberg et al., 1989). Reality-oriented interventions in intensive psychotherapy also serve the function of limiting impulsive or self-damaging actions and helping the person consider response contingencies which she was not considering while emotionally aroused.

Because the psychoanalytic conception of certain "ego functions" is so similar to the cognitive-behavioral concept of "self-regulation," the kinds of interventions I will describe may seem familiar to many psychodynamic clinicians. These techniques may diverge from standard psychodynamic practice, however, in that they are based on an analysis of the component cognitive and affective processes believed to generate borderline symptoms - rather than on more general formulations about "ego functions" or "object relations"-and hence are targeted at specific processes. Explicit, theory-guided, consistent use of such techniques does not necessarily follow from a conceptualization of borderline disorders as an arrest at the rapprochement subphase of separation-individuation (Mahler, Pine, \& Bergman, 1975), an arrest at the developmental period in which splitting is the primary mechanism of defense (Kernberg, 1975), a failure in the formation of a cohesive self through transmuting internalization or optimal frustration (Buie \& Adler, 1982; Kohut, 1977), or a battleground for conflagrations among competing object-relational part-units (Masterson, 1976). The following techniques described represent examples of such interventions, and are clearly not intended to serve as an exhaustive list. 


\section{Cognitive-Behavioral Strategies for Self-Regulation}

Many cognitive-behavioral techniques are well-suited to borderline patients because of their explicit focus on self-regulation (see Kanfer \& Karoly, 1972; Karoly \& Kanfer, 1982). Meichenbaum's (1977) approach to teaching impulse control to impulsive children, for example, focuses on the progressive internalization and routinization of self-instructions to stop, look, listen, delay, plan, and implement an appropriate strategy. Various sequenced directions of this sort are at first provided concretely by the therapist, but this function is gradually assumed by the patient, who at first instructs himself verbally and ultimately goes through these steps unconsciously.

Certain standard cognitive techniques, such as those directed against "catastrophizing," or "black-and-white" or "either-or" thinking (Beck, 1976), are particularly appropriate for treating borderline affect regulation. The therapist points out the way these cognitive patterns are activated under certain circumstances and helps the patient reality-test them when they emerge. Borderline patients are not easily "argued out of" thcir distortions, and are seldom able when their emotions are aroused to engage in the kind of reality-oriented "collaborative empiricism" (Beck, 1985) of cognitive therapy. Consequently, the therapist needs to respond empathetically to the patient's intense affect state while simultaneously addressing distortions that may both reflect and intensify it (e.g., "I know it feels like that, but is that really likely?").

\section{Red Flags and Black Dots}

One patient (a borderline adolescent) came to develop, in therapy, a list of "red flags" which signal to him that a pathological process is in progress. We began the list with a series of words which, if he heard himself utter them, should serve as a red flag. The list included "bitch," "asshole," "perfect," "total ___" and other words that signaled all-or-nothing thinking and spiraling affects. Gradually, he came to add other psychological processes and behaviors to his list of red flags. For example, when he felt himself wanting to use cocaine, he would recognize that he was running from an intense affect or expressing a dynamic behaviorally, particularly since his father's death had been cocaine related. Whereas, initially, over the course of many sessions, I had to point out red flags repeatedly, he eventually began noticing them in his daily life as well as in sessions.

While identification of red flags was a necessary first step, the patient somewhat tauntingly asked me the first time we began using this terminology, "So then what? What am I supposed to do with it?" I wondered with him what he and I do together when his affects begin to spiral out of control in sessions, to which he replied, "Be analytical." This, then, became the second step after identifying a red flag, namely, inhibiting action long enough to examine his associations and the meanings, fears, wishes, or conflicts generating the emotion. Doing so slowed him down, which is critical for borderline patients, who have difficulty inhibiting action and exercising self-observation when affectively aroused. It also fostered a comforting identification with the therapist which was itself soothing and helped him respond appropriately to whatever concern caused the emotion rather than responding globally and diffusely to what felt like a blinding affective signal.

It should be noted that this technique, which relies on insight in the psychoan- 
alytic sense, was much more concretely worked out with the patient than psychodynamic clinicians are usually comfortable doing. For example, we spoke directly in terms of a two-step process and gave labels to each of the steps. Sometimes when he was not in a session but began to feel his affects spiraling out of control, he was encouraged to write my "part" in the therapeutic dialogue, or ask himself questions as I would. When in sessions he would start to spiral and helplessly flail around waiting for me to find the magic to calm him, I was initially very explicit in helping him begin to assume some of my functions by asking what I would say or ask right now. While borderline patients are very sensitive to condescension or to "techniques" that do not feel like part of a genuine relationship, concreteness is of the essence when their affects are poorly modulated because their capacity to think abstractly and to sequence thoughts or actions becomes grossly impaired. Kernberg and his colleagues (1989) similarly advocate labeling role relationships that repeatedly emerge in the treatment. Ideally, the need for concreteness, as in speaking of red flags or using labels for various processes or "states of mind" (Horowitz, 1987), should gradually and spontaneously subside, as the patient internalizes the process and routinizes the procedure of spotting and responding to dysregulation (although when severely stressed, the patient may once again require concrete interventions).

Another patient with mixed borderline-narcissistic pathology experienced imagined interpersonal slights with such intensity that "the world" would become an undifferentiated evil mass that included stupid, malevolent, faceless people out to make him suffer. At such times he was very difficult to reach because the therapist, too, was part of this undifferentiated mass. Eventually, I employed the metaphor with him that when his depression, rage, or humiliation became aroused, the world would collapse into one big "black dot," and that he needed to let me out of the dot momentarily so we could discuss it. With repeated use of this metaphor he began to have some recognition of this process as it would occur in the therapy hours, and would spontaneously offer, "I'm black-dotting again." "Red flags" and "black dots" are, of course, simply examples of the way structured interventions may emerge from metaphors developed in treatment hours.

\section{Modeling}

Affective-motivational aspects of object relations pathology may be addressed through careful use of modeling, as when a patient tries to "cut a deal" regarding some slightly shady handling of third-party payment. In such cases, one can effectively both examine the meaning of the patient's attempt to draw the therapist into collusion with a fraudulent action and also demonstrate to the patient a way of handling ethical issues and inhibiting need-gratification in a way that may be quite foreign to the patient's experience. Although such interventions are often understood in psychoanalytic psychotherapy as "limit setting" (i.e., as treatment parameters), they can also be very valuable in modeling ways of handling impulses or emotions. Modeling affect-regulatory processes can also be useful. For example, the adolescent described above had a penchant for pushing all the buttons on the elevator on his way up to my office while he was an inpatient. One day, when he did this, he evidently "pushed my buttons" as well, since annoyance apparently flashed across my face. He, of course, was quite attuned to any signs that would 
indicate that he had achieved the desired result, which he also feared. In the process of exploring the meanings of his testing me this way, I disclosed that I had, indeed, been annoyed, but that I had then begun thinking about several possible explanations of his behavior. He was astonished both that a person could pause and self-reflect when getting angry and that one could still think clearly enough to generate dynamic hypotheses in such circumstances. Similarly, whether one thinks of this in terms of modeling or identification, the patient's internalization of the therapist's relative calm and analytic attitude in the face of his or her escalation can be an important source of therapeutic change.

\section{Limited Self-Disclosure}

While one must be extremely careful to examine both countertransference motives and transference meanings whenever one self-discloses to a borderline patient, judicious use of self-disclosure can at times be helpful and, at other times, indispensible. Distorted attributions, often of a malevolent nature, are pathognomonic of borderline pathology and of personality disorders more generally, and these invariably arise in the treatment situation. The therapist's disclosure of his or her actual motives alongside exploration of the meanings and causes of the patient's attributional distortions can be crucial in helping the patient reality-test his or her inferences; it can also sometimes help prevent premature termination resulting from malevolent attributions.

Borderline personalities are often products of chaotic homes in which parental figures behaved inexplicably and erratically (see Ludolph et al., 1990). Therapists whose methods remain mysterious or ambiguous may be playing into pathological family dynamics as well as childhood fantasies. Particularly with these patients, whose boundaries were often violated psychologically or sexually as children, initial transference interpretations should usually be prefaced with some kind of explanation of why the therapist is focusing on this relationship at all (such as, "What you feel in here with me can sometimes be very similar to what you feel with other people in your life, so it can often be helpful to look at what's happening in this relationship," or "What a person feared or hoped for in his relationships with his parents as a child often seems to come up again in his relationships with other people later on. I wonder if the way you seem to have such a hard time trusting me has anything to do with the way you talked about feeling that you couldn't rely on anyone when you were a kid."). Borderline patients usually will not, however, maintain appropriate boundaries in the therapeutic relationship, so one must be very circumspect with self-disclosure.

\section{Humor}

A well-timed and judicious use of humor can also be valuable in working with borderline patients, not only in helping build an alliance, but in counteracting runaway affect. The role of the therapist in this instance is something like the role of government in Keynesian economics; i.e., when normal equilibration processes cannot prevent a downward and self-reinforcing spiral, an exogenous factor must intervene to prevent depression. Humor can also be helpful at times in addressing manipulations, because it signals to the patient that the therapist knows what 
the patient is trying to do and will not go along with it, but neither will he be destroyed by it nor rejecting in response to it.

\section{Enhancing Perspective-Taking}

Much of the work therapists do with borderline patients centers on enhancing capacity for perspective-taking, particularly under conditions of affective arousal. The tendency of these patients to think egocentrically requires specific therapeutic focus, as when the therapist questions the patient's view that "everyone" in his life is out to hurt her, or helps the patient see why her employer was distressed when she persistently called in sick with ten minutes' notice. Such interventions are particularly useful in dealing with transference issues because these issues are affective and live, both partners in the experience have firsthand knowledge of the interactions involved, and the therapist can directly confront and, at times, contradict the patient's attributions.

\section{Examining Cognitive Structures, Patterns, and Processes}

Interventions aimed at increasing the complexity, integration, and differentiation of representations of people and at altering pervasive, dysfunctional attributional patterns are typically cognitive in focus but are a standard part of psychoanalytic psychotherapy with borderline patients. Kernberg and his colleagues (1989) have masterfully described the way one addresses simplistic and poorly integrated representations. At times labeling a problematic cognitive pattern directly can be helpful, with borderlines as well as with other personality disorders. One patient had the pervasive fantasy that she was always about to hit the last straw with people which would convince them that she was stupid, worthless, and should therefore be abandoned. Not surprisingly, this served as a tremendous resistance to treatment, since she censored every word for fear that the next utterance would lead to this unfortunate state of affairs. This "last straw" fantasy rested upon both a simplistic, overly global self-representation ("I am worthless"), a masochistically distorted attribution ("if this person hasn't abandoned me yet, it is because he hasn't noticed my awfulness yet"), and an egocentric attribution ("everyone sees me the same way I do"). As in a traditional psychoanalytic treatment, the masochistic dynamic was examined in terms of the conflicts underlying it. On the more cognitive side, we came to label the egocentric pattern of attribution "Ms. C's First Law," namely that people see things exactly as she does, and tested the reality of her attributions on numerous occasions when she or I became aware that she was applying this "law." The lack of complexity of her self-representation, particularly when she was depressed, was examined both cognitively (looking at how this simplistic schema affects her life) and dynamically (looking at her motivations at particular times for evoking it). On one occasion, when she was most distraught and terrified that her next "stupid" words would be the last straw, I graphically illustrated a component of my own schema of her, which included numerous hierarchically organized subcomponents, and noted the way a single comment at any point would be assimilated into this structure. I pointed out a critical difference between her cognitive structure and mine, that mine was not so brittle or one-dimensional that it would collapse in the face of a few utterances on her part. This intervention allowed her to begin discussing the pathologically harsh moral standards that paralleled her brittle self-representation, as well as her fear that some of her comments were not only stupid but aggressive, and hence 
back into a more analytic examination of a number of very rigid impulse-defense constellations. While the use of a graphic illustration in psychoanalytic therapy is certainly unconventional (although this patient was an adolescent), it can be effective when affect is intense and thinking has regressed to a morc concrete level. Confrontation of other attributional patterns is standard fare in the psychoanalytic treatment of borderline patients, although not always conceptualized as such. For example, altering the pervasive expectations of victimization is perhaps the most critical aspect of transference analysis advocated by Kernberg with borderline patients.

\section{Integration of Multiple Technical Strategies}

Addressing problematic attributional processes, representations of self and others, and dynamic conflicts often occurs in tandem. One patient, who had tremendous difficulty with self-esteem, would, when frustrated, apply to herself overly simplistic and undifferentiated trait labels such as "stupid." She was unable in such moments to remember ways in which she was not all-dumb or to generate alternative hypotheses for failures. On one occasion she had recently returned to college after taking a high school equivalence examination, and decided after doing poorly on a test that she was stupid and would never complete the term. She became terribly distraught, viewing this failure as one more instance of her worthlessness. Her wish to do well, and her profound disappointment at her grade, led not only to activation of a global and univalent self-schema but also to an abridgement of the attribution process (i.e., a failure to consider other explanations). What was most useful for her in the session, and what allowed her to calm down and begin to cope more effectively (e.g., by planning to go to the library that night instead of picking up a man at a bar, as she had intended), was my pointing out the activation of a global and univalent self-representation, and wondering about her failure to consider the impact on her grade of her never having completed high school, which would have tempered her attribution of stupidity as the sole explanation for failure. (I was comfortable in intervening in this way, which could be interpreted as simply bolstering a rationalization, because I had her WAIS-R protocol in my file drawer.)

These kinds of interventions frequently lead back to more dynamic interventions. For example, this patient, having calmed considerably in the session, did not, in fact, go to the library as planned and rapidly began fretting about failure on the next test. Examination of her failure to follow through revealed her fear that she could not meet my expectations of success, just as she felt she could not meet her father's as a child, and her consequent attempt to bring failure under her control by doing something to bring it about. She promptly acted herself out of school and then confronted me with precisely the situation with which she had confronted her father so many times, namely that she had raised his hopes and then dashed them. In my stance toward school, I had unthinkingly moved into the role of an advocate and thus clearly diverged from neutrality, and in this case, I paid for it. Through this experience, however, the patient gained insight into the way she enlists "accomplices" (Wachtel, 1987) who recapitulate with her many painful experiences from her past.

Use of cognitive-behavioral techniques in the context of intensive psychotherapy neither interferes with transference-oriented work nor does it irrevocably "contaminate the transference." Treatment of the adolescent boy described here in 
various examples, for instance, centered not only on examination of his alternately idealizing, devaluing, manipulating, and feeling victimized by the therapist, but also on a prominent homosexual transference. Therapeutically, one can work with a patient's experience or distortions of the implications of various interventions on the part of the therapist, just as one works with patients' interpretations and distortions of a relatively neutral stance. For example, careful analytic work with a patient who experiences a technical decision as manipulative may uncover a projection of his own wishes to manipulate, an instance of devaluation or expectation of victimization, or a tendency to treat an overdetermined action as if it were the product of a single (usually hostile) motivation. Further, transitory assumption of a slightly different role by the therapist may allow access to more of the patient's transferential paradigms. Wachtel (1987) has cogently discussed transference implications of behavioral interventions in psychoanalytic psychotherapy in an essay on the limits of therapeutic neutrality entitled, "You Can't Go Far in Neutral." Therapists who work with borderline patients are always caught between the Scylla of recapitulating neglectful or affectively ingenuine parenting through what the therapist experiences as neutrality, and the Charybdis of recapitulating poorly bounded, overinvolved parenting motivated by countertransference feelings. Unfortunately, the course must be charted anew for each patient, with a very imperfect compass.

\section{THE LIMITS OF PSYCHOANALYTIC AND COGNITIVE-BEHAVIORAL INTERVENTIONS WITH BORDERLINE PATIENTS}

As this article has suggested, consideration of cognitive-behavioral interventions may suggest avenues of intervention not typically emphasized in the psychodynamic psychotherapy of borderline patients. The need for cognitive-behavioral supplementation of this sort stems from some of the limits of the psychodynamic paradigm.

\section{Limitations of Psychoanalytic Approaches}

First, while psychoanalysis proposes that conscious uncovering of unconsciously evoked patterns (such as defenses, conflicts, and relationship paradigms) is critical to therapeutic change, it lacks a comprehensive theory of the way conscious decisions in the face of insight become transformed into adaptive automatic or unconscious patterns. Whereas in psychoanalysis, automaticity is often associated with pathology, in cognitive psychology automaticity is viewed as a prime characteristic of skilled functioning which distinguishes experts from novices (see Anderson, 1985). In the case of borderline patients, mere conscious recognition of a pattern, even in the face of strong affect (or perhaps, especially in the face of strong affect, in contradistinction to neurotics), does not typically lead to change in fundamental patterns of functioning (such as affect regulation) without considerable practice, trial and error, and conscious structuring of mental processes. Psychoanalytic theory and technique focus primarily on one important class of affect-regulatory mechanisms - unconscious defenses - without adequately addressing conscious techniques for self-regulation other than "insight."

Second, psychoanalytic theory and practice tend not to focus adequately enough on implementation of change, which does not typically follow automatically from insight, even in neurotics. Insight into the causes of an irrational fear, for example, 
may alter the balance among anxiety, wishes to approach the feared object, expectations of efficacy in overcoming the fear, and expectancies about the dangers involved in doing so. However, insight alone often will not provide enough impctus to approach the object and, hence, to begin disconfirming the anxious expectancies or to inhibit automatic elicitation of an affective reaction associatively connected to a cognitive representation of the phobic stimulus (see Wachtel, 1987). Similarly, insight into the neurotic motivations for depressive self-denigration may not be entirely effective in inducing the person regularly to access positive self-representations because thinking positively about the self is linked to aversive affects and cognitive-affective schemas that are activated automatically (such as fears that if one does not blame oneself one must attribute blame instead to an abusive parent, who has been defensively shielded from responsibility or idealized). In such cases, thinking positive thoughts about the self is tantamount to a phobic stimulus that must be "desensitized." Implementation of insight-driven change must be a particular target of therapeutic work with borderline patients, whose counter-motivations and difficulty implementing anything can often derail a treatment.

Third, the psychoanalytic preference for motivational explanations underplays the role of cognition and social learning in the etiology and maintenance of psychopathology. Kernberg, for example, views splitting as a defense against the anxiety evoked by forming more complex representatives (Kernberg et al., 1989), as when a patient refuses to see any imperfection in his therapist to avoid intolerable feelings of disappointment and rage. While splitting is often motivated in this way, this is only one explanation of what is probably a multidetermined phenomenon. Splitting could result from deficits in affect regulation without any defensive function if strong affects recruit univalent or mood-congruent representations. Research suggests that mood-states broadly influence cognition, including encoding and retrieval of schematic information (Blaney, 1986; G:lligan \& Bower, 1984; Isen, 1984). An inability to regulate rage or sadness, for example, could produce a tendency to make malevolent attributions or to activate powerful and global negative self-representations and could inhibit recognition of alternative or more complex explanations. Splitting can also reflect social learning. The patient described earlier with the "last straw" fantasy had a severely borderline mother (whom I knew to be so by direct observation) whose representations were so split and transitory that the patient literally never knew whether she would be facing the "totally loving mother" or the "totally attacking mother," or whether she (the child) would do something that would make her totally bad in her mother's eyes - the "last straw." Parental or familial projections onto the child and other family members may similarly lead to internalization of rigid roles and split views of the self and others (such as "the evil child") (see Shapiro et al., 1975).

Fourth, the confusing place of affect in psychoanalytic theory (see Rapaport, 1953) has led to a relative failure to focus theoretically on a core aspect of borderline pathology, namely the experience and regulation of affect. Theoretical and clinical attention have instead focused on drive considerations and objectrelational formulations which, though useful, draw attention away from what should be an equally important and discrete focus of therapeutic attention.

Finally, the holism endemic to psychoanalysis, which views character as a system of interdependent processes and understands symptoms as particular manifestations of more general conflicts or personality dynamics, focuses the clinician's attention away from specific processes (e.g., particular aspects of borderline 
attributions) and onto more general phenomena (e.g., "object-relational pathology," "separation issues"). In Kernberg's system, all borderline symptoms are ultimately derived from the patient's defensive efforts to keep good and bad representations separate (see Kernberg et al., 1989). Holism, in this respect, is one of the strengths as well as weaknesses of psychoanalytic theory, just as the atomism and attention to microprocesses inherent in cognitive-behavioral theory and technique have both costs and benefits.

\section{Limitations of Cognitive-Behavioral Approaches}

While cognitive-behavioral approaches can be usefully integrated into psychoanalytic psychotherapy, as an alternative to intensive psychotherapy they have limitations which are particularly salient in work with personality-disordered patients, cspecially borderlines. First, cognitive-behavioral approaches underestimate the complexities of motives and countermotives. For example, at a recent conference, a prominent cognitive-behavioral clinician was asked to comment on a case of an adolescent diabetic from a broken home who kept throwing himself into ketoacidosis. After recommending education about diabetic control and being apprised that this boy knew more about diabetes than his parents or his therapist and yet still kept hiding candy bars, the speaker suggested that perhaps peer pressure motivated the boy to want to hide his diabetes in order to be like his peers. This level of understanding of motivation is not far advanced of American popular culture; it ignores the complex motives of a boy who had been physically abused, had abused himself on numerous occasions and developed self-abusive motivations, and seemed to be tempting fate to prove his immortality in the face of a serious illness. The cognitive-behavioral understanding of motivation, with its pragmatic, rationalistic bent inherited from the Enlightenment, British empiricist philosophy, and twentieth century American culture, is particularly inadequate in dealing with borderline patients. Anyone who has used operant techniques with inpatient borderlines is aware of the paradoxes of "reinforcement" in patients with strong masochistic trends who are often "reinforced" by punishment.

Second, and related, cognitive-behavioral approaches considerably underestimate the complexities of fantasy and unconscious experience. One suicidal borderline patient told me in the context of a research interview that she had recently been in treatment but had not disclosed to her therapist any of the aggressive fantasies which tormented her, and which she had disclosed to me in a single interview. When asked why not, she said she is not a nice person, whereas her therapist is, and this was a "nice therapy" in which one did not discuss such things. Similarly, a patient who was evaluated for "trouble getting along with people" provided indications in the first interview of a perversion. He had several very gruesome sexual fantasies, some of which involved his prior therapist, a cognitive therapist he had seen for over a year. He had numerous fantasies of raping and killing her which he had never discussed with her and about which she had never asked. Instead, I received a treatment summary from her that glowingly described his progress in their work on his "social skills" and "workaholism." In treating severe personality disorders, psychotherapy that stays at the level of skills training and role-playing to overcome problems such as "relating to people" and "workaholism" is particularly problematic because these patients are often terrified of their fantasies and are certain that the therapist is equally afraid of dealing with 
them. The focus of cognitive approaches is primarily on conscious or semiconscious habits of thought, with minimal attention to deeper levels of meaning and experience and to possible motivations for these habits. Cognitive theories also lack a concept of defense, addressing instead only conscious coping mechanisms, which are only one form of affect-regulatory mechanism.

Third, cognitive-behavioral theories lack a concept of levels of object relations and ego functioning which permit a distinction between neurotic symptoms and severe character pathology. In cognitive-behavioral literature (at least until very recently), depression is depression, phobias are phobias, and no further diagnostic distinctions are necessary for treatment. Sophisticated cognitive-behavioral clinicians recognize these distinctions and adapt their treatment strategies accordingly, but they do so without the aid of theory or of any conceptualization of character structure. Less experienced clinicians operating in this theoretical no-man's-land with character disorders are prone to making gross technical errors, as in the case of a borderline patient referred to me after a suicide attempt who had been treated solely with relaxation training, or a narcissistic patient whose aggressive outbursts and difficulty attaching made him friendless and jobless who was treated with cognitive therapy aimed at helping him see that he is not as unlovable and unemployable as he accurately recognized himself to be.

Fourth, although attention to specific pathological processes is one of the strengths of the cognitive-behavioral approach, it is also a weakness when one begins to consider interactions of various cognitive and affective processes that may render treatment of any one process alone highly problematic. Targeting for treatment the presumed perspective-taking deficits of delinquents or antisocial personalities may be of little value if one does not simultaneously target the pathology of investment in relationships that would make such individuals care about the perspective of others. Cognitive "deficits" of this sort may be only one part of a broader pathology of attachment involving a system of interacting cognitive, affective, and motivational processes.

Finally, although cognitive concepts could prove useful in understanding certain transferential processes (Goldfried, 1989; Singer, 1985; Wachtel, 1981; Westen, 1988), cognitive-behavioral approaches fail to address the complexities of the interpersonal process between patient and therapist. For borderline patients, much of whose pathology is interpersonal, this imposes a severe limitation. This can be seen in the failure of the therapist in a previously cited example to examine the patient's sadistic fantasies toward her, which recur in other relationships, or the failure of the "nice therapist" to examine the patient's object-relational paradigm of hating herself, protecting a significant other from her destructive wishes, and consequently remaining isolated from people with whom she longs to be intimate but simultaneously keeps at arm's length.

The field of psychotherapy has long been polarized between advocates of psychodynanic and cognitive-behavioral approaches. Perhaps it would be therapeutic for both patients and the profession for some healing of this split to take place in the treatment of patients for whom splitting and polarization are a prominent aspect of their pathology.

Acknowledgements - The author would like to thank Christopher Peterson, Kenneth Silk, Paul Wachtel, and several anonymous reviewers for their comments on a draft of this paper. 


\section{RËFRENCES}

Anderson, J. R. (1985). Cognitive psychology and its implications (2nd ed.). New York: Freeman.

Ancironulis, P. A., Glueck, B. C., Stroebel, C. F., Vogel, N. G., Shapiro, A. L., \& Aldridge, D. M. (1980). Organic brain dysfunction and the borderline syndrome. Psychiatric Clinics of North America, 4, 47-66.

Benjamin, J., Silk, K. R., Kohr, N. E., \& Westen, D. (1989). The relationship between borderline personality disorder and anxiety disorders. American Journal of Orthopsychiatry, $\mathbf{5 9}, 46 \mathbf{1}-467$,

Beck, A. T. (1976). Cognitive therapy and the emotional disorders. New York: International Universities Press.

Beck, A. T. (1985). Cognitive therapy, In H. I. Kaplan \& B. J. Sadock (Eds.), Comprehensive textbook of psychiatry (pp. 1432-1438), 4hi ed. Ballinure: Willians and Wilkins.

Beck, A. T., Freeman, A., et al. (1990). Cognitive therapy of personality disorders. New York: Guilford Press.

Beiman, B. D., Goldfied, M. R., \& Norcross, J. (1989). The movement toward integrating the psychotherapies: An overview. American Joumal of Psychiatry, 146. 138-147.

Blaney, P. H. (1986). Affect and memory: A review. Psychological Bulletin, 99, 229-246.

Blat, S. J., Quinlan, D. M., Chevron, E. S., McDonald, C., \& Zuroff, D. C. (1982). Dependency and self-criticism: Psychological dimensions of depression. Journal of Consulting and Clinical Psychology, $\mathbf{5 0}$, $113-124$.

Bowlby, J. (1969). Attachment and loss: Vol. 1, Attachment. New York: Basic Books.

Buie, D., \& Adler, G. (1982). The definitive treatment of the borderline patient. International foumal of Psychoanalytic Psychotherapy, 9, 51-87.

Clarkin, J. F. (1983). Prototypic typology and the borderline personality disorder. Joumal of Abnormal Psychology, 92, 269-275.

Cowdry, R. W., \& Gardner, D. L. (1988). Pharmacotherapy of borderline personality disorder, Archives of General Psychiatry, 45, 111-119.

Ekstein, R., \& Wallerstein, J, (1954). Observations on the psychology of borderline and psychotic children. Psychoanalyic Study of the Child, 9, 344-369.

Exner, J. E. (1986). Some Rorschach data comparing schizophrenics with borderline and schizotypal personality disorders. Joumal of Personality Assessment, 50, 455-471.

Freeman, A., \& Leaf, R. C. (1989). Cognitive therapy applied to personality disorders. In A. Freeman, K. M. Simon, L. E. Beutler, \& H. Arkowitz (Eds.), Comprehensive handbook of cognitive therapy, (pp. 403-433). New York: Plenum.

Gardner, D. C, \& Cowdry, R. W. (1985). Alprazolam-induced dyscontrol in borderline personality disorder. American Joumal of Psychiatry, 142, 98-100.

Gartner, J., Hurt, S. W., \& Gartner, A. (1989). Psychological test signs of borderline personality disorder: A review of the empirical literature. Journal of Personality Assessment, 53, 413-421.

Gilligan, S. G., \& Bower, G. H. (1984). Cognitive consequences of emotional arousal. In C. E. Izard, J. Kagan, \& R. B. Zajonc (Eds.), Emotion, cognition, and behavior. Cambridge: Cambridge University Press.

Glat, M. (1988). Borderline syndrome: Cognitive and behavioral treatment for adolescents. Part II $\rightarrow$ Treatment and practice. Carrier Foundation Letter, 132, 1-3.

Goldberg, S. C, Schultz, P. M., Resnick, R. J., Hamer, R. B., \& Friedel, R. O. (1986). Borderline and schizotypal personality disorders treated with low-dose thiothixene vs. placebo. Archixes of General Psychiatry, 43, 680-686.

Goldfried, M., \& Hayes, A. (1989). Can contributions from other orientations complement behavior therapy? The Behavior Therapist, 12, 57-60.

Gunderson, J. G. (1984). Borderline personality disorder. Washington, DC: American Psychiatric Press.

Gunderson, J. G. (1986). Pharmacotherapy for patients with borderline personality disorder. Archives of General Psychiatry, 43,698-700.

Gunderson, J. G., \&: Elliott, G. R. (1985). The interface between borderline personality disorder and affective disorder. American Journal of Psychiatry, 142, 277-288.

Herman, J., Perry, J. C., \& van der Kolk, B. A. (1989). Childhood trauma in borderline personality disorder. American Journal of Psychiatry, 146, 490-495.

Horowitz, M. (1987). States of mind: Configurational analysis of inditridual psychology (2nd Ed.), New York: Plenum Press.

Hunt, H. F. (1977). Behavioral perspectives in the treatment of borderline patients. In P. Hartocollis (Ed.), Borderline personality disorders. New York: International Universities Press.

Isen, A. (1984). Toward understanding the role of affect in cognition. In R. S. Wyer \& T. K. Srull (Eds.), Handbook of social cognition, Vol. 3. Hillsdale, NJ: Erlbaum. 
Kanfer, F. H., \& Karoly, P. (1972). Self-control: A behavioristic excursion into the lion's den. Behavior Therapy, 3, 398-416.

Karoly, P., \& Kanfer, F. H. (Eds.) (1982). Self-management and behavior change: From theory to practice. New York: Pergamon Press.

Kernberg, O. (1975). Borderline conditions and pathological narcissism. New York: Aronson.

Kernberg, O. (1984). Severe personality disorders: Psychotherapeutic strategies. New Haven: Yale University Press.

Kernberg, O. F., Selzer, M. A., Koenigsberg, H. W., Carr, A. C., \& Applebaum, A. H. (1989). Psychodynamic psychotherapy of borderline patients. New York: Basic Books.

Klein, D. (1977). Psychopharmacological treatment and delineation of borderline disorders. In P. Hartocollis, (Ed.), Borderline personality disorders: The concept, the syndrome, the patient (pp. 365-384). New York: International Universities Press.

Knight, R. (1953). Borderline states. Bulletin of the Menninger Clinic, 17, 1-12.

Kobak, R. R., \& Sceery, A. (1988). Attachment in late adolescence: Working models, affect regulation, and representations of self and others. Child Development, 59, 135-146.

Kohut, H. (1977). The restoration of the self. New York: International Universities Press.

Kroll, J, \& Ogata, S. (1987). The relationship of borderline personality disorder to the affective disorders. Psychiatric Developments, 2, 105-128.

Lazarus, A. A. (1981). The practice of multimodal therapy. New York: McGraw-Hill.

Lehrer, P., Schiff, L., \& Kris, A. (1971). Operant conditioning in a comprehensive treatment program for adolescents. Archives of General Psychiatry, 25, 515-521.

Liebowitz, M. R., Stone, M. H., \& Turkat, I. D. (1986). Treatment of personality disorders. In A. J. Frances \& R. E. Hales (Eds.), American Psychiatric Association Annual Review, Vol. 5. Washington, DC: American Psychiatric Press.

Linehan, M. (1987a). Dialectical behavior therapy for borderline personality disorder: Theory and method. Bulletin of the Menninger Clinic, 51, 261-276.

Linehan, M. (1987b). Dialectical behavior therapy in groups: Treating borderline personality disorders and suicidal behavior. In C. M. Brady (Ed.), Women in groups. New York: Springer.

Linelian, M. (1987c). Dialectical behavior therapy: A cognitive behavioral approach to parasuicide. Journal of Personality Disorders, 1, 328-333.

Looft, W. R. (1972). Egocentrism and social interaction across the lifespan. Psychological Bulletin, 78, 73-92.

Ludolph, P., Westen, D., Misle, B., Jackson, A., Wixom, J., \& Wiss, F. C. (1990). The borderline diagnosis in adolescents: Symptoms and developmental history. American Journal of Psychiatry, 147, $470-476$.

Mahler, M., Pine, F., \& Bergman, A. (1975). The psychological birth of the human infant: Symbiosis and individuation. New York: Basic Books.

Masterson, J. F. (1976). Psychotherapy of the borderline adult. Ncw York: Brunncr/Mazcl.

Meichenbaum, D. (1977). Cognitive behavior modification: An integrative approach. New York: Plenum Press.

Menninger, E., Mayman, M., \& Pruyscr, P. (1963). The vital balance. New York: Viking Press.

Millon, T. (1982). Disorders of personality: DSM-111, Axis II. New York: John Wiley \& Sons.

Ogata, S., Silk, K. R., Goodrich, S., Lohr, N. E., Westen, D., \& Hill, E. (1990). Childhood abuse and clinical symptoms in borderline personality disorder. American Journal of Psychiatry, 147, 1008-1013.

Perry, J. C., \& Cooper, S. H. (1986). A preliminary report on defenses and conflicts associated with borderline personality disorder. Journal of American Psychoanalytic Association, 34, 863-893.

Perry, J. C., \& Klerman, G. (1980). Clinical features of borderline personality disorder. American Journal of Psychiatry, 137, 165-173.

Peterson, C., \& Seligman, M. E. P. (1984). Causal attributions as a risk factor for depression: Theory and evidence. Psychological Review, 91, 347-374.

Piaget, J. (1951). The language and thought of the child. New York: Humanities Press (Original work published, 1926).

Pilkonis, P., \& Frank, E. (1988). Personality pathology in recurrent depression: Nature, prevalence, and relationship to treatment response. American Journal of Psychiatry, 145, 435-441.

Rapaport, D. (1953). The psychoanalytic theory of affect. In M. Gill (Ed.), The Collected Works of David Rapaport. (pp. 476-512). New York: Basic Books.

Shapiro, E. R., Zinner, J., Shapiro, R. L., \& Berkowitz, D. A. (1975). The influence of family experience on borderline personality development. International Review of Psycho-Analysis, 2, 399-411.

Sheehy, M., Gondsmith, I., \& Charles, E. (1980). A comparative study of borderline patients in a 
psychiatric outpatient clinic. American Journal of Psychiatry, 137, 1374-1379.

Siever, L. J., \& Davis, K. L. (1985). Loward a dysregulation hypothesis of depression. American Journal of Psychiatry, 142, 1017-1031.

Silk, K. R., Lohr, N. E., Westen, D., \& Goodrich, S. (1989). Psychosis in borderline patients with depression. Journal of Personality Disorders, 3, 92-100.

Silk, K. R., Lohr, N. E., Ogata, S., \& Westen, D. (1990). Borderline inpatients with affective disorder: Preliminary follow-up data. Journal of Personality Disorders, 4, 213-224.

Singer, J. (1985). Transference and the human condition: A cognitive-affective perspective. Psychoanalytic Psychology, 2, 189-219.

Soloff, R., \& Millward, J. W. (1983). Developmental histories of borderline patients. Comprehensive Psychiatry, 24, 574-588.

Soloff, P. H., George, A., Nathan, R. S., Schulz, P. M., Ulrich, R. F., \& Perel, J. M. (1986). Progress in pharmacotherapy of borderline disorders: A double-blind study of amitriptyline, haloperidol, and placebo. Archives of General Psychiatry, 43, 691-697.

Swenson, C. (1989). Kernberg and Linehan: Two approaches to the borderline patient. Journal of Personality Disorders, 3, 26-35.

Waclitel, P. (1981). Transference, schema, and assimilation: The relationship of Piaget to the psychoanalytic theory of transference. Annual of Psychoanalysis, 8, 59-76.

Wachtel, P. (1987). Insight and change. New York: Guilford.

Waldinger, R. J. (1987). Intensive psychodynamic therapy with borderline patients: An overview. American Journal of Psychiatry, 144, 267-274.

Waldinger, R. J., \& Gunderson, J. G. (1984). Completed psychotherapies with borderline patients. American Journal of Psychotherapy, 38, 190-202.

Westen, D. (1985). Self and society: Narcissism, collectivism, and the development of morals. Cambridge: Cambridge University Press.

Westen, D. (1988). Transference and information processing. Clinical Psychology Review, 8, 161-179.

Westen, D. (1989). Are "primitive" object relations really preoedipal? American Journal of Orthopsychiatry, 59, 331-345.

Westen, D. (in press). Social cognition and objcct rclations. Psychological Bulletin.

Westen, D. (1990). Toward a revised theory of borderline object relations: Implications of empirical research. International Journal of Psycho-Analysis, 71, 661-693.

Westen, D., Lohr, N., Silk, K., Gold, L., \& Kerber, K. (1990). Object relations and social cognition in borderlines, major depressives, and normals: A TAT analysis. Psychological Assessment: A Journal of Consulting and Clinical Psychology, 2, 355-364.

Westen, D., Ludolph, P., Block, J., Wixom, J., \& Wiss, F. C. (1990). Developmental history and object relations in psychiatrically disturbed adolescent girls. American Journal of Psychiatry, 147, 1061-1068.

Westen, D., Ludolph, P., Lerner, H., Ruffins, S., \& Wiss, F. C. (1990). Object relations in borderline adolescents. Journal of the American Academy of Child and Adolescent Psychiatry, 29, 338-348.

Westen, D., Ludolph, P., Misle, B., Ruffins, S., \& Block, J. (1990). Physical and sexual abuse in adolescent girls with borderline personality disorder. American Journal of Orthopsychiatry, 60, 55-66.

Westen, D., Moses, M. J., Silk, K. R., Lohr, N. E., Cohen, R., \& Segal, H. (1989). Quality of depressive experience in borderline personality disorder and major depression: When depression is not just depression. Department of Psychology, University of Michigan (unpublished paper).

Winnicott, D. (1971). Playing and reality. New York: Basic Books.

Wixom, J. M. (1988). The depressive experiences of adolescents with borderline personality disorder. Unpublished doctoral dissertation, University of Michigan.

Zanarini, M. C., Gunderson, J. G., \& Frankenberg, F. R. (1990). Cognitive features of borderline personality disorder. American Journal of Psychiatry, 147, 57-63. 